\title{
An experience of technology transfer success of software for children with disabilities
}

\author{
Janio Jadán-Guerrero \\ Student of the Doctoral Program in Computer Science, Universidad de Costa Rica \\ Universidad Tecnológica Indoamérica, Centro de Investigación, Innovación y Desarrollo, \\ Quito, Ecuador \\ janiojadan@uti.edu.ec
}

\begin{abstract}
This article describes an experience of technology transfer success of software for visually impaired children in Ecuador. The starting point was the personal experience of the author with his daughter with special needs. This fact allowed the development of AINIDIU (Intelligent agent for visually impaired children). AINIDIU is a computer-based technology to facilitate the interaction between visually impaired children and computers. The background, technological structure and evaluation of AINIDIU are described in this article. In addition, the process of transfer technology is described, in which a cooperation agreement was signed among Vice presidency of Ecuador, FENCE (Organization of blind people) and Universidad Indoamérica. In this context, Computer Science students installed the software in approximately 1,000 laptops donated by program "Misión Manuela Espejo" supported by Vice presidency of Ecuador. FENCE and students of Education career were responsible for training to teachers of schools, in the use of technologies and Virtual Learning Platform for blind people. As result of the process visually impaired children of 22 provinces of Ecuador were beneficed. The author motivated by this rewarding experience continues with new projects in the Doctoral Program in Computer Science of Universidad de Costa Rica.
\end{abstract}

Keywords: AINIDIU, Microsoft agents, text-to-speech, visually impaired children, inclusive learning, technology transfer.

\section{Introduction}

Ecuador is a country in South America with an approximate population of $15^{\prime} 000,000$. The proportion of population with disabilities represents $11 \%$ ( 1 ' 650,000 people). The rate of people with visual impairments is $21.5 \%$ (354,750 people) and the rate of children between 0 to 10 years old is $2 \%$ (7095 children) [1]. For these children, the support is very important for their development in the society. It is a great challenge for Ecuadorian government, organizations or people committed to help children with special needs.

This article describes an experience among university, organizations and government who joined to work for blind and visually impaired children. It is well known that children who have remaining vision need specialized magnification lenses or electronic enlargement devices. Through them, children can obtain information about the world in which they grow. Visually impaired children need to learn specialized skills for social interactions, independent mobility, personal grooming, food preparation, money management, and other tasks. In this sense, computer-based technologies can play an especially important role to support these children [2].

AINIDIU is a computer-based technology designed for blind and visually impaired children. The name was directly inspired from the acronym in Spanish: Agente Inteligente para NIños con DIscapacidad visUal, and its pronunciation in Spanish is like the phrase in English: "I need you". Certainly, this thought crosses by the mind of visually impaired children, because they need support for any task of their daily lives. AINIDIU uses a metaphor of a virtual friend using an assistance agent for introduce to children in the use of computers [3]. 
This article is organized as follows. A description of the background and motivation is given in Section 2. A description of technical and educational features is presented in Section 3. The process of socialization and transfer technology are described in Section 4. Finally conclusions and future work are presented in Section 5.

\section{Background and motivation}

This section introduces the motivation and story behind the ideas to create computer-based technology to support children with special needs. It is due to the personal experience of the author, who has a wonderful, adorable, and sweet girl with visual and cognitive impairments, Carolina. Since she was born in 2001, the author and his family have experienced barriers related to aspects of social and educational inclusion. They have witnessed the lack of institutions, professionals and resources to treat children with special needs. The problems and frustrations that this family experienced for some years, gave rise to new opportunities. The experience of the author in Computer Science; the experience of his wife in Psychology; and the ability of their first son in the use of technology and videogames, were factors that contributed in the creation of entertainment-education strategies for Carolina that made it worth the effort.

The use of entertainment-education strategies were part of the courses dictated by the author in some universities. His students learned Computer Science with interest and entertainment and they were motivated all time to participate in different challenges and competitions [5].The motivation was essential to change the mentality of students in order they can create software to solve problems for their environment. For example, in Artificial Intelligence and Compilers courses they programmed a virtual pet using Microsoft Agents. They had to teach theory concepts to their pet. At the end of the course, each pet had to answer the questions made by the professor. In Image Processing course students enjoyed creating animated tales for children with stop motion technique. All of these ideas were considered to relate with the needs of children with disabilities.

The author has developed some projects for children with special needs supported by the Research Center of Universidad Tecnológica Indoamérica [3]: AINIDIU in 2009, which has the ability to interact with a blind child through a speech synthesizer and a screen reader. HELPMI in 2010, which provides communication support for speech therapists and language impaired children through tablets and smart phones. CANDI in 2011, a web platform to support parents of children with disabilities. LUCKI in 2012, which is a software to support learning of children with intellectually impairments through Microsoft Kinect device [4].

Regarding the importance of incorporating Information and Communications Technology (ICT) among children with special needs, interviews were conducted with professionals from the main institutions of the city of Quito who have been working with disabled people. Among of them, CONADIS (Consejo Nacional de Discapacidades) in which they coordinate five national federations in disabilities [1]. All the interviewed people showed high interest in the idea to create ICT for children with special needs. They considered to begin with a project for visually impaired children, because this population has been underserved. These children have reduced mobility at home; many have few friends outside of the family. They also experience significant levels of discrimination within the society. In order to obtain more information about this group of children, some institutions related to blind people were visited:

1) FENCE (Federación Nacional de Ciegos del Ecuador) [10].

2) MARIANA DE JESUS, Institute for the Deaf and Blind

3) CEFOCLAC (Centro de Formación y Capacitación Laboral para Ciegos).

4) AGORA (Aulas de Gestión Ocupacional de la Región América Latina en Ecuador)

5) RECAPT S.A (private company that employs blind people in its call center)

As result of the interviews, an important list of problems was detected in visually impaired people -from daily life activities to the more complex social activities, like studying or getting a job. They confront a number of visual challenges every day, especially children that couldn't access some resources like books in Braille format or other tools to support to their independence. In this context, the Director of FENCE was interested in the development of a software to help visually impaired children in the use of computers. In order to design a basic interface, a visually impaired expert on JAWS (Job Access With Speech) and NVDA (NonVisual Desktop Access) was introduced to work together. The starting point for this initiative was the born of AINIDIU. The next section describes the software architecture and the main characteristics of the AINIDIU software. 


\section{AINIDIU SOFTWARE}

AINIDIU (Intelligent agent for visually impaired children) plays the role of computer assistant in training computer skills of blind and visually impaired children. The software interacts with the children through entertainment activities. The system contains a number of challenges, and gives children opportunity to explore and discover. These activities help visually impaired children to identify the keyboard and learn with the help of an assistant. The educational features, the design of the architecture and the evaluation of usability are described in this section.

\subsection{Educational Features}

Educational software presents challenges for children with disabilities in different ways. An interdisciplinary work is important to know how integrate the technology and pedagogy [1][6][7]. In this sense, we created an interdisciplinary team, in which we combined our experience in Computer Science, Psychology and the help of a visually impaired expert on technologies for blind people. The participation of Carolina and her brother helped to imagine the sceneries for family inclusion.

We made some interviews to teachers, therapists and parents of visually impaired children. The ten more important features listed below have been defined to create educational strategies for these children:

1. The target group for the software to be developed is for children between 5 and 12 years old.

2. The information provided by the software should encourage playful activities that generate interest and curiosity in children.

3. The interaction between the child and the computer must provide a user-friendly interface based on motivational audio.

4. The language and information for the interface must be clear and easy to interpret.

5. Software should foster reading documents through stories by a synthesized voice or audio books.

6. The interaction with keyboard is important to identify the different keys.

7. The keys of the keyboard could be associated with a sound (numbers, letters, animals or objects) in order to educate the child's ear.

8. Educational games are important to improve the interaction with other children.

9. The incorporation of a virtual character can help to guide children trough a metaphor of virtual friend.

10. Parents, teacher or therapist must have access to change music, sound, graphics or document files.

According to the requirements listed above, we reviewed several studies conducted by researchers from other countries. In Paraguay, for example, the authors designed LUCIA, a system of agents to accompany blind children while listen a hypermedia story. The Lucia System is intended to assist in the process of strengthening the sensory motor skills of visually impaired children and offers guidelines for teachers on student performance in the game. [6]. In Brazil the software DOSVOX is a package with utilities that give blind persons a chance to use a computer as a normal user by reading with a computer-generated voice what appears on the screen. DISCAVOX is a tool to provide easy accessing to electronic mail or newspapers reading. FINANVOX is an educational software tool, that supports for people living with some degree of visual impairment in the process of teaching and learning, particularly in the field of financial mathematics [7]. Other authors in Chile designed a model for development of mobile applications based on videogames focused in the learning of visually impaired children. They concluded that the model is a fundamental contribution for developers of videogames in mobile devices because it supports the development of orientation and mobility skills for visually impaired users [8]. In Argentina a Specialized Information System (SIS) for visually impaired and blind children in preschool (3-6 years) was designed. The system named "La valijita viajera" consists of a multimedia application over a set of teaching activities aimed at supplementing the work of teachers [9]. In Spain the Fundación ONCE (Organización Nacional de Ciegos Españoles) is a referent foundation that provide services for the blind and people with serious visual impairment. They have their own research centre of technology, CIDAT (Centro de Investigación, Desarrollo y Aplicación Tiflotécnica). This organization has developed software for visually impaired children, among them "El árbol mágico de las palabras" or "La pulga locadia" which was included in the games section of AINIDIU [11]. This background and experiences have been considered to design a prototype adapted to Ecuadorin reality. 


\subsection{Design and specifications}

In this stage, with the main educational features we proposed a design based on some technical specifications. The ten more important specifications considered for AINIDIU are listed below:

1. The information has structured in text files instead of a database engine to facilitate software portability.

2. Microsoft Visual Studio and C\# language were used to take advantage of the Microsoft Agents libraries.

3. Microsoft Agents with SAPI libraries were used to provide a synthesized voice.

4. The software was designed to run from a USB storage device in order to provide a maximum portability.

5. The interface was designed to use ARROWS, ENTER, SPACEBAR, TAB, PAGE UP, PAGE DOWN, HOME, END, and DELETED keys in order children get familiarized with JAWS.

6. In the contents of the software were included documents, stories, music, audio books, games and sounds.

7. The system has the capacity to incorporate information not available in its database by a feedback module.

8. The interface was also designed to provide accessibility for children with residual vision.

9. The system was designed to be configurable and scalable to personalize the needs of children.

10. The software is compatible with Windows XP and higher.

Understanding that visually impaired children have few friends outside of the family, we considered to develop a metaphor of a "virtual friend". This virtual friend has the capacity to interact with children through "questions and answers" or tips to explore the computer. This interaction would help to enjoy a sense of familiarity and collaboration with other children. Other idea considered in the design is that ANIDIU can be carried on a USB bracelet. In this case when a child inserts their virtual friend in any computer, the software executes automatically with all information of the child.

The software architecture and its user interface are shown in Figure 1. The diagram in a) shows the architecture divided in six modules. The figure in $\mathrm{b}$ ) shows the USB bracelet, the user interface and menu options.
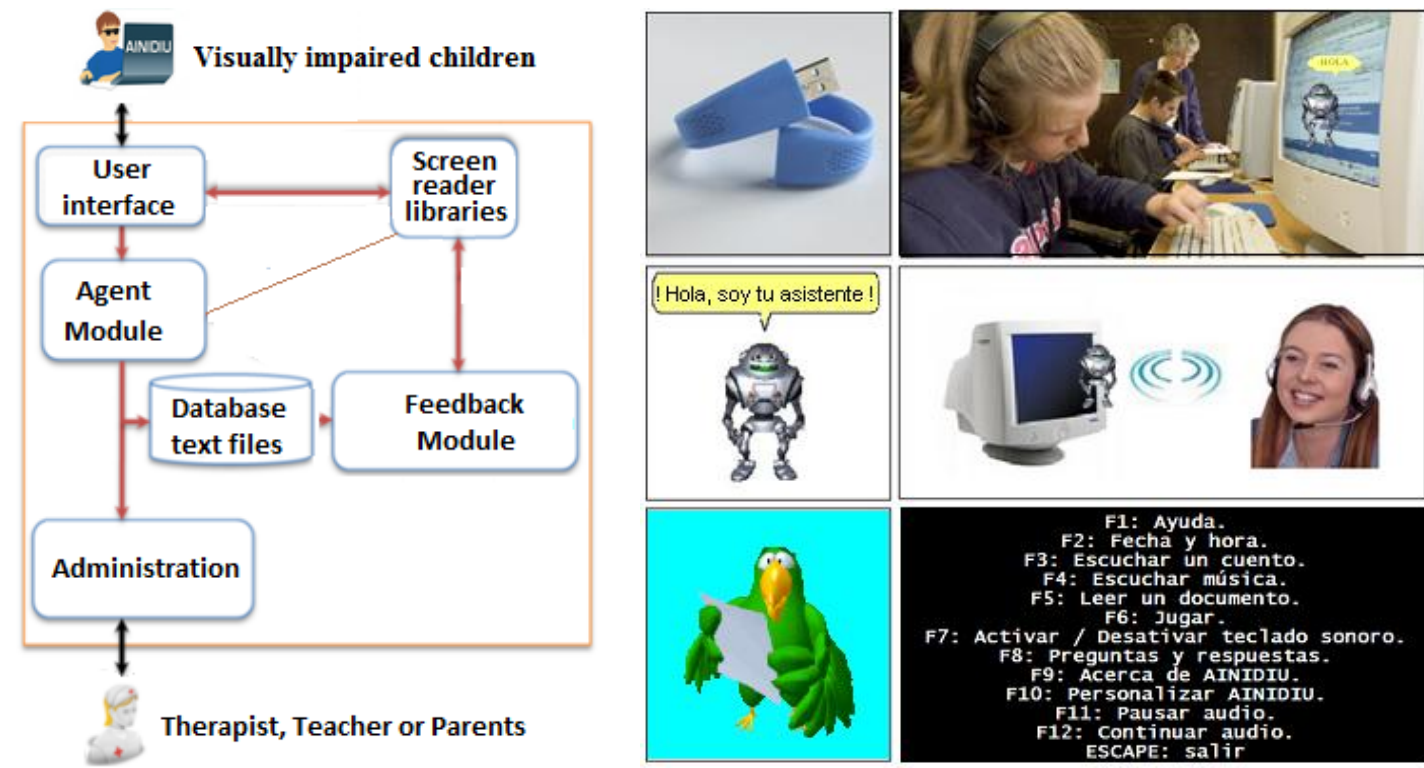

Figure 1: a) Architecture of AINIDIU. b) AINIDIU software can be carried on a USB bracelet and run on any computer with Windows operating system.

The user interface module is a simple screen in which text and images are shown. The navigation can be performed by the arrow or function keys. The menu is configured with twelve options: F1 Help, F2 Date and time, F3 Listen a 
story, F4 Listen music, F5 Read a text document, F6 Games, F7 Active or deactivate the sound keyboard, F8 Question and Answers, F9 Contacts for help, F10 Settings, F11 Stop audio, F12 play audio and ESC exit. There also are submenus that can be navigated by left and right arrow.

In the Agent module a manager of Microsoft Agent is used in the communication between the user and the computer. Microsoft Agents are animated characters that simulate how a person would communicate. It uses the SAPI API libraries in Spanish language and creates an easy way to retrieve data from the user by keyboard or from the knowledge representation database. This module also manages the libraries of the NVDA screen reader. It helps to complement the functionality of a screen reader. To make the character speak and move, the commands are as follows:

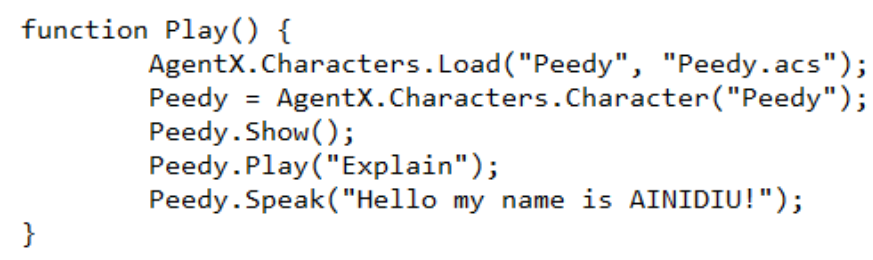

Figure 2 shows a block diagram of the architecture and implementation of AINIDIU. The knowledge representation and retrieval is a set of TXT files: In base.txt a special language based on strings is developed for easy search, the sign ">" separates the keywords with answers. In comunes.txt a list of questions words (qué, que, cual, quién, etc.), articles (el, la, lo los, las, etc.), pronouns (he, she, we, etc) and other common words (sabes, te, etc.) are not considered by the natural language parser. In menus.txt a list of options are stored for user interface. The SAPI Runtime provides a high-level interface between an application and speech engines. The two basic types of SAPI engines are text-to-speech (TTS) systems and Recognition Engine. TTS systems synthesize text strings and files into spoken audio using synthetic voices. Recognition Engine convert human spoken audio into readable text strings and files [12]. AINIDIU uses only TTS Engine.

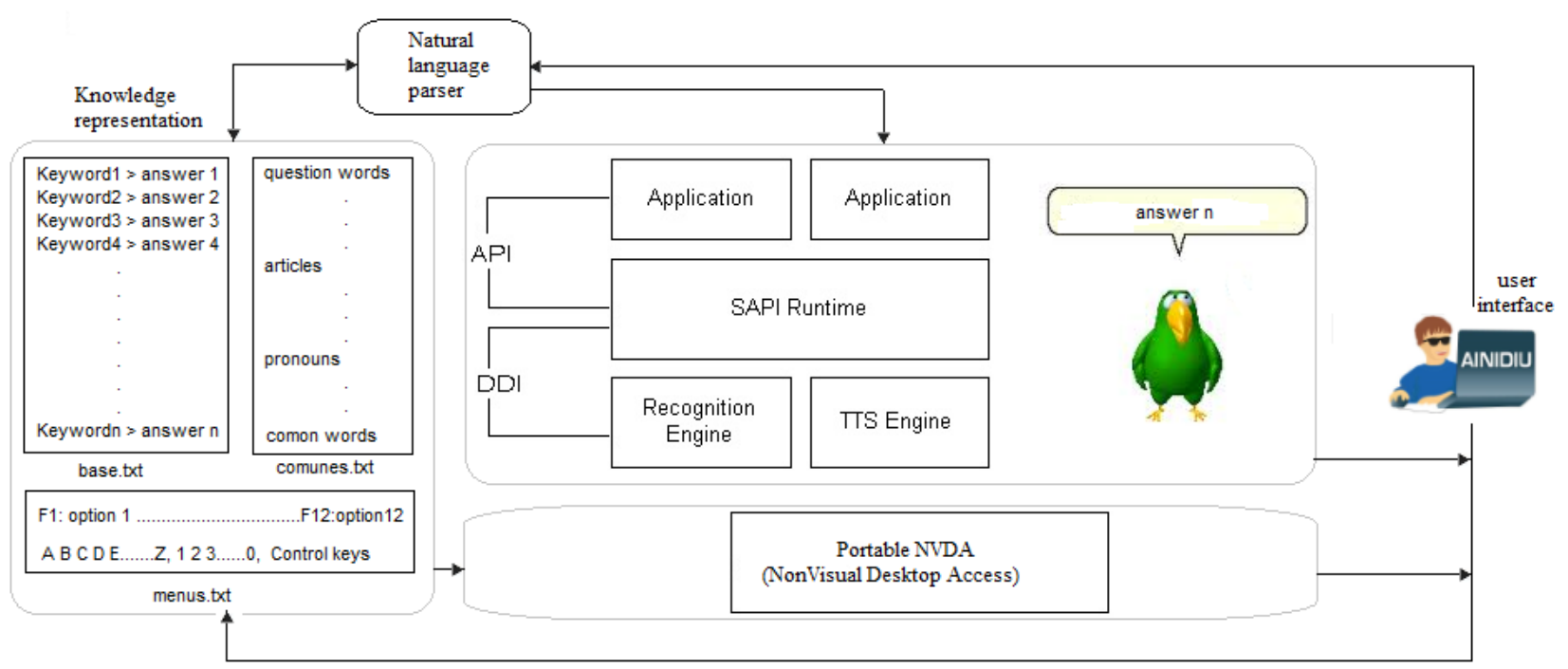

Figure 2: Block diagram representing AINIDIU architecture and implementation.

The feedback module interacts with children through questions and answers. A child can write a question, the character spells each letter, word or phrase. The module divides the phrase in tokens to extract the keywords. They are searched in the base.txt file. When any keyword coincides with a record, the information after the sign ">" is showed and pronounced by the character. If there are not any coincidence, the character asks for an answer. The child writes his answer and it is saved at the end of the base.txt file. The screenshot a) in Figure 3 shows an example of the game of "Questions and Answers". The screenshot b) in Figure 3 shows a text file in which children can listen while the agent reads line by line. The child can write and save his own files. These activities make children develop their learning in a natural and playful way[6][8][9]. 

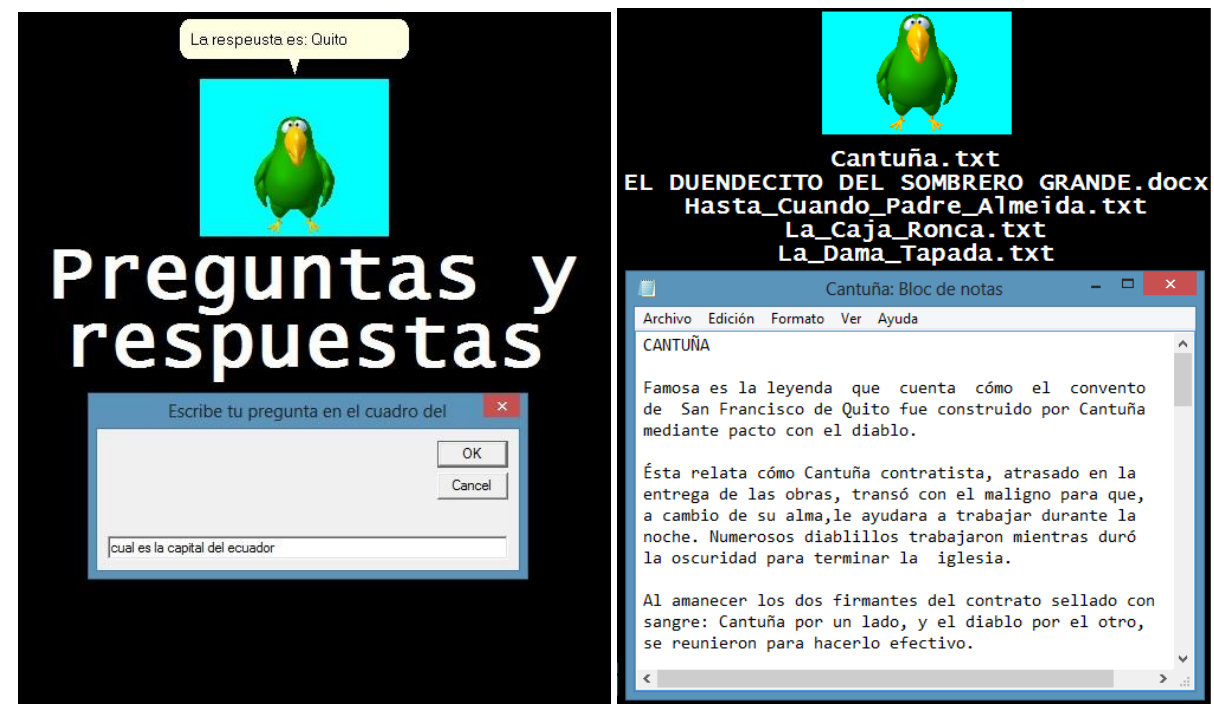

Figure 3: a) Children can interact with their virtual friend b) AINIDIU can read or write text documents.

The interaction through games is essential to prevent children from getting bored [8]. AINIDIU can execute simple games in EXE or SWF formats. Children can guess the image showed in screen trough the sound associated to each key of the keyboard, for example, the sound of a clock is played when the "R" key is pressed. The screenshot in a) of Figure 4 shows this case. Another playful activities are the games. The Figure 4 in b) shows a screenshot of "La Pulga locadia" designed by ONCE Foundation of Spain. In which children move the car with arrow keys guided by the feedback of the agent.
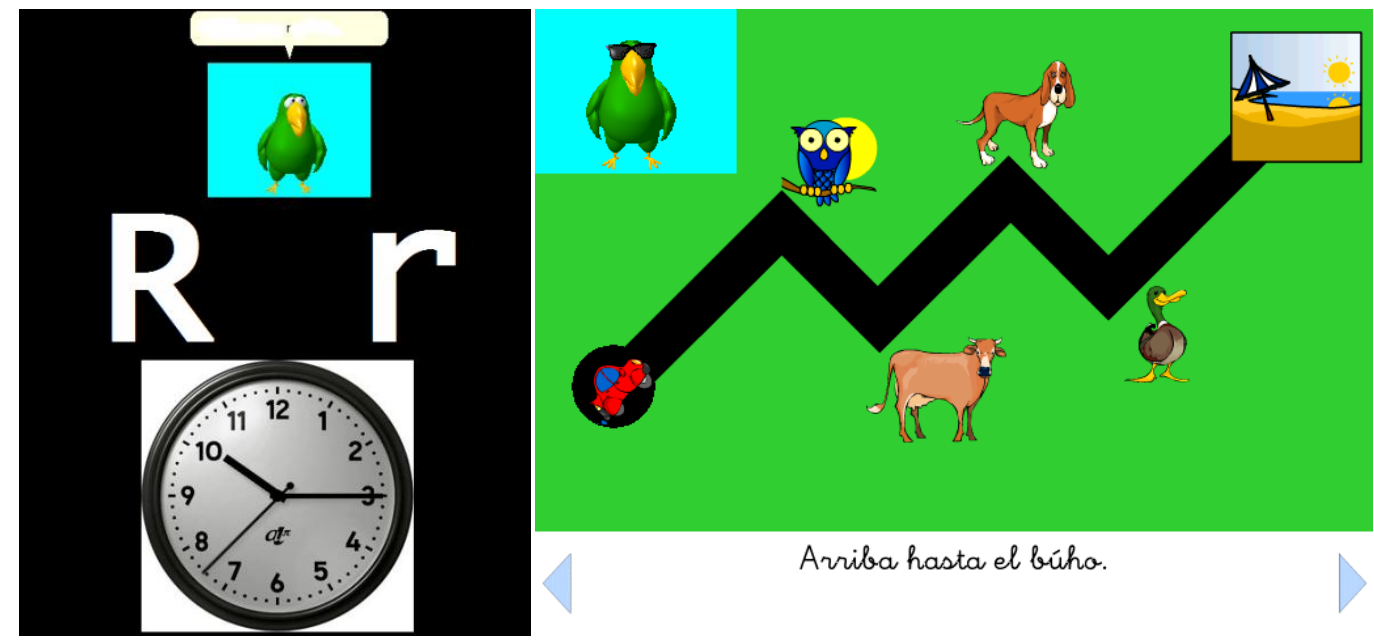

Figure 4: a) When any key is pressed an image and sound are presented. b) The game "La Pulga Locadia" challenges to children the use of arrow keys.

The Administration module of AINIDIU was designed for non-technical users. Teachers, therapists and parents of visually impaired children can create teaching strategies to promote their inclusion in educational environments. This module is structured in a set of folders and files that are easy to modify or replace. The Figure 5 shows the structure. The audiolibros folder contains files in MP3 or WAV format, the system shows in the menu all the files that the folders have. The chars folder contains some Microsoft Agents Character files in ACS format. The name of the file can be changed in the file configura.txt, The docs folder contains files in TXT format. They can be stories or literature according of the region where child lives. The system also supports WORD or PDF files if the software is installed in the system. The imagenes folder contains files in JPG format, each file has the name of each letter of the keyboard, The juegos folder contains files of simple games in EXE or SWF formats. The musica folder contains 
files in MP3 or WAV format. The NVDA folder contains the portable version of the screen reader NVDA. The sonidos folder contains files in WAV format, each file has the name of a letter of the keyboard.

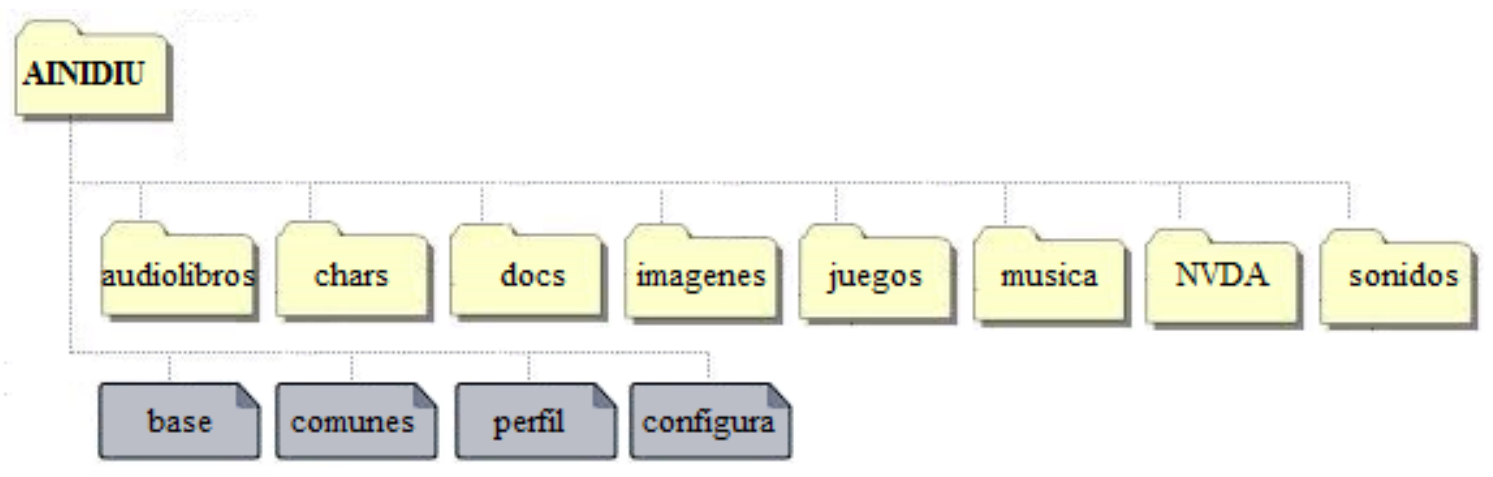

Figure 5: Structure of directory as part of Administration module of AINIDIU

The files (documents, images or audio) of these folders can be changed externally and the user interface module dynamically reads them. The information can also be changed in the files: base.txt (knowledge representation), comunes.txt (words used for the natural language parser to extract keywords), perfil.txt (data of each child) and configura.txt (configuration options). Considering that an audio book is a helpful resource for blind and visually impaired children, because it incorporates environment sound according the stories [6]. We included Ecuadorian literature in the basic configuration of AINIDIU. In this context, we have the opportunity to talk with a Ecuadorian author of literature for children. As result of this initiative the author Juan Carranza Carrillo signed an agreement with Universidad Indoamérica, in which he compromised to gave the rights of his books. We challenged to create our own audiobook. In the record participated near of twelve people, Carolina, her friends and the research team. After two months of hard work the audiobook "El Duendecito del sombrero grande" was included into AINIDIU software [24].

\subsection{Evaluation}

In this section we describe the process carried out in order to evaluate the functionality and usability of AINIDIU. We focused mainly on three stages of evaluation: (1) During the development, (2) After the first prototype and (3) After the last version of AINIDIU.

During the development of the prototype a functionality test was done, at this stage some meetings with psychologist of Universidad Indoamérica and teachers of the school "Mariana de Jesus" were held. The interviews, conducted over a period of two months that helped to enhance various aspects of the system: Its visual interface, its audio interface, the dialogues and types of the animated characters, the structure of stories, and teaching activities that could be incorporated for children between 5 and 12 years old. Also our blind expert performed some evaluations, allowed the identification of some usability issues. The main issue identified concerns about the audio interface. When he performed an action that requires listen the instructions through the synthesized voice of the MS agents, the speed of the speech was faster for children. In these situations, a configuration of speed should have. This configuration was considered to create an input in configura.txt file. Other issues were found related to the screen reader and the way of navigation that were enhanced.

After the first prototype we conducted a first usability evaluation of AINIDIU. In the usability test we used a qualitative metric to measure how satisfactory the children experience is [15]. In this context we used the usability inspection method to understand whether the software was easy to use and could potentially become a part of the visually impaired children lives [27]. The first step taken to perform this evaluation was to assembled the evaluation team. This team should be formed by a group of four evaluators: Developer, psychologist, teacher and a blind person. The developer and the blind expert had knowledge in usability, while the psychologist and teacher had knowledge in the field in which the prototype will be used, in this case in educational area. The evaluators had a set of questions to guide the exploration of the interface as well as a set of common user tasks. The second step was to assembled the group of children to be evaluated. Finding children with different abilities and visually impaired conditions was an extremely hard mission. The solution was to talk with the director of Mariana de Jesús Institute, 
who helped to select six students. Four of them had the permission of their parents. It was crucial to the success of the evaluation. In the group there were two children that have used a computer before (experts) and two that have never used it (novice). Three of them were blind children and one had remaining vision. The third step was to carry out the evaluation in two sessions in different days. In the first session, we explained the general propose of AINIDIU and the evaluation was conducted by showing the main user interface to each one, without explain how it works. We observed how they discovered the different activities with just the support of the virtual friend. For expert children, the interaction was natural, however for novice children it was a new experience. They could navigate by the menu in an intuitive way. After, we interviewed them over their first impression. The main comment identified were that they were motivated by the activities, especially for games. In the second session, the four children have to do specific tasks. They were able to perform the tasks and they were motivated to personalize the information. Overall, for novice and experts children, the prototype software was widely accepted, from the point of view of usability and performance of this tool, declaring in a $100 \%$ that this tool is easy to use.

After the final version of AINIDU, we designed a usability test based on a quantitative metric to measure how the system helps to enhance the short-term memory [15]. Memory is a key component of cognition and plays an integral role in cognitive development of visually impaired children because they have to memorize the different options or commands [6][8][9]. In this context we required the help of some psychologists. A teacher and four students of the Psychology Career of Universidad Indoamérica participated in the evaluation during three months. They requested to conduct a quasi-experiment in "Mariana de Jesús" Institute. The Director gave them the opportunity to evaluate the software in one course. In the course there were ten visually impaired children of 7-10 year-old. The parents of five of them gave their authorization. The psychologists used the test of short-term (Immediate) Auditory Memory (IAM), which is a test to measure the logical memory (e.g., reciting and recalling the content presented in a story) [28]. A pre-test was applied before children use ANIDIU. In five sessions, the psychologists reviewed some activities with five children. They focused in two of them: To listen stories and to play games. After the five sessions a post-test was applied. The Table 2 shows the results.

Table 1: IAM Test Results

\begin{tabular}{cccc}
\hline No. & Child & Pre-Test & Post-Test \\
\hline 1 & Joe & 105 & 235 \\
2 & Stalin & 122 & 224 \\
3 & Erick & 13 & 100 \\
4 & Martha & 76 & 138 \\
5 & Carmen & 25 & 235 \\
& TOTAL & $\mathbf{3 4 1}$ & $\mathbf{9 3 2}$ \\
& PUNTUACTION & $\mathbf{1 7 \%}$ & $\mathbf{4 7 \%}$ \\
\hline
\end{tabular}

The last two columns of the table show the index obtained in the Pre-test and Post-test of the Immediate Auditory Memory. This index is known as Auditory Memory Index (AMI) which is a measure of the ability to listen an oral information, repeat it immediately, and then recall the information after a 20 to 30 minute delay. For children No.1 for example, the index of the pre-test is in the range (AMI =105). That is compared to other individuals of his age, Joes's auditory memory capacity is good. Stalin's auditory memory capacity is very good (AMI=122). Martha's auditory memory capacity is deficient $(\mathrm{AMI}=76)$, while Erick and Carmen is insufficient. The post-test column has also the AMI but we can see that the evaluation generated a contribution in each case. In the total of the punctuation the contribution was of $22,09 \%$, which indicates that the activities of AINIDIU software were usefully to increase the cognitive response in auditory memory for children with visual impairments.

Finally, the team of psychologists conducted an interview to three teachers of the institute. They focused in the flexibility of use and the usability to adapt the information according their needs. From the interviews they found that theses teachers were able to create learning activities for their students easily and quickly. In addition, they considered that the resources for teaching visually impaired children are appropriate to improve their learning.

These evaluations made possible to the research team validate the assumption that AINIDIU is easy to use and it could improve the learning and the user experience of blind and visually impaired children, as well as what teachers suggest to enhance the activities of AINIDIU aiming to contribute to society. 


\section{Socialization and technology transfer}

In 2012, we participated in the "Third National Science Conference UTCiencias 2012", a regional conference organized by Universidad de Cotopaxi. It was an opportunity to socialize our projects and participate in the contest of research projects. We presented the report "Information and Communication Technologies for children with special educational needs" and made a demo of AINIDIU, HELPMI (software that emulates a language of words, in order to help a child with language impairment) and CANDI (a web platform that allows the diffusion of technological innovations and services to people with special educational needs). In the conference participated forty projects in some disciplines of science and technology. Public and Private universities from the centre region of Ecuador presented their research projects during one day. The jury was composed of five well-known professionals in science and industry. The jury visited each stall and evaluated every exhibitor. After a rigorous evaluation, our project obtained the first prize in social impact category[16].

As part of the prize, the winners of five categories were published in one of the most important newspaper of Ecuador. The article "Information and Communication Technologies for children with special educational needs" was published in an especial edition on Education in "El Comercio" newspaper. [17]. This publication helped that people know about technologies for children with disabilities. One important thing to stress is that at that time the Vice President of Ecuador Lenin Moreno was one of the world's few disabled national leaders. This paralysis gave him insight into the needs and concerns of disabled people, especially those in Ecuador.

In May 2012, we also presented the paper "ANIDIU, CANDI, HELPMI: ICTs of personal experience" in the "IEEE 2012 WEA - Workshop of Engineering Applications" organized by the Universidad Distrital de Colombia [3] [18]. The diffusion of these technologies and the supporting of FENCE allowed that the Government of Ecuador took interest in AINIDIU for the Mission titled "Manuela Espejo". This program aims to provide specialized technology for visually impaired children in 22 provinces of the country. The aim was to deliver nearly one thousand children, a school back with a laptop with AINIDIU, calculator and talking clock. Other tools, such as: abacus, strip, punch and tracking stick were included.

On October 16, 2012 The Vice President of the Republic of Ecuador signed a tripartite agreement between the FENCE and Universidad Indoamérica. It was an important step in which Academy, government and organizations combine efforts for visually impaired children. The agreement contemplated that students of Universidad Indoamérica participate in this social program. For example, students of Computer Science be responsible for installing the software, students of Design Career be responsible for the design of the different elements of user interface and students of Education Career be responsible for training teachers of schools where the tools were given. The execution of this agreement is described below.

For transferring scientific findings from Universidad Indoamérica to schools for the purpose of further development we took some meetings with a responsible of the three organizations: FENCE, Vice presidency and University. In October 2012 took place the first phase of software installation. Forty students of Computer Science, Industrial Engineer and Business Administration Careers installed 474 Core i5 laptops. The AINIDIU Software was installed and the screen reader NVDA that provides access to most of the functionality of Windows through a voice synthesizer was configured. The photograph a) of Figure 6 shows how students and volunteers installing AINIDIU in the computers. 

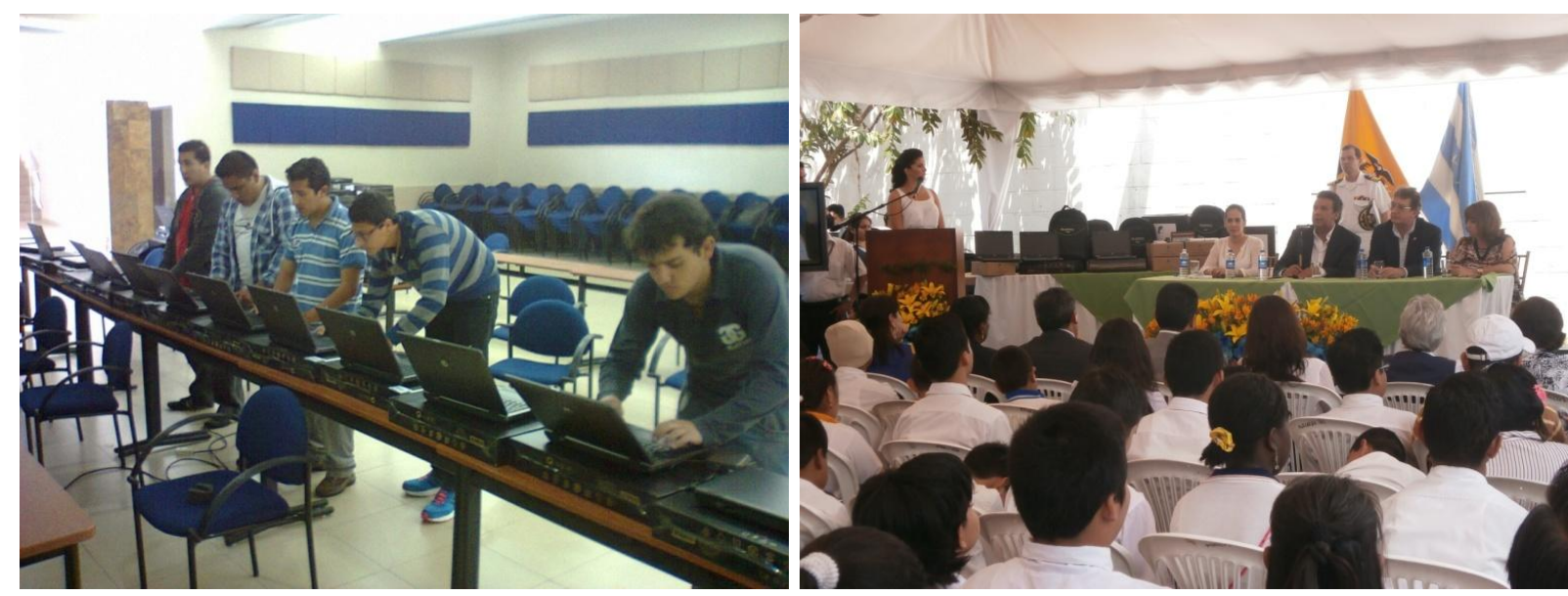

Figure 6: a) Students of Universidad Indoamérica install the AINIDIU Software. b) The Vice president of Ecuador in the first delivery of computers and technology for blind children.

In November, 2012, the Vice President of Ecuador Dr. Lenin Moreno, inaugurated in Guayaquil the first delivery of technical aids for children with visual disabilities. Seventy five students from several rural schools were the beneficiaries of this program. The Director of FENCE, Dr. Luis Narvaez and the Rector of Universidad Indoamérica Eng. Saul Lara Rector were in the event. The b) photograph of Figure 6 shows the opening ceremony.

In December 2012 and January 2013 approximately 1000 computers were installed. In addition they were delivered in the different schools of blind children around of all Ecuador. At the same time students and teachers of Universidad Indoamérica were training to the teachers of these schools [19,20,21]. In July 2013, in order to establish technical, technological, human and academic mechanisms to strengthen inclusive education at the higher level, for the benefit of persons with disabilities and their families, CONADIS and Universidad Indoamérica proceeded to the signing of cooperation agreement [22]. This new project has a number of alternatives to address the issue of disability worked from a virtual platform, which will serve as a means to train members of public and private institutions, organizations and general public who wish to know about the field of disability [23].

\section{Conclusions and future work}

In this article highlights the major conclusions of the experience between university and government institutions. The starting point was the personal experience of the author and his family which motivated the development of software for children with disabilities. The experience of the author in Computer Science; his wife specialized in Children Psychology and a blind expert in the use of technology helped to build interesting initiatives in order to connect public and private institutions related to disability. The participation of children as Carolina, her brother and other children in the development and evaluation process was a grateful activity. The result of this effort was a contribution in the creation of entertainment-education strategies for visually impaired children that made it worth the effort.

The diffusion of the technologies developed in Universidad Indoamérica in scientific conferences allowed to know of the research and its results. These results helped that FENCE and Vice-presidency of Ecuador want to implement the software in their program "Misión Manuela Espejo". The agreement signed beneficed to approximately 1000 visually impaired children distributed in 22 provinces of Ecuador.

Currently, the university has begun new projects focused on the training of these tools. There has also been an approach to the vice presidency of Ecuador in order to provide these technologies and strengthen its welfare programs. Technology transfer allowed the expansion of the use of informatics in society. There is much to do and envision possible future research to consolidate AINIDIU, HELPMI, CANDI, LUCKI and TIC@ULA with actual technology.

This rewarding experience of working with children with disabilities and people committed to change the life of these children, has allowed to open new opportunities and challenges. Thus, in February 2013 the author obtained a doctoral scholarship in the Doctoral Program in Computer Science of Universidad de Costa Rica. The scholarship is 
supported by the Ecuadorian government through the SENESCYT (Secretaría Nacional de Educación Superior, Ciencia y Tecnología) and Universidad Indoamérica.

As part of the Doctoral Program in Computer Science, the author pretends to research new methods to develop novel technologies in the integration of children with intellectual disabilities. The aim of the research is to determine what elements are important in an efficient design of non-traditional user interfaces. This research involves the experience of experts in special education to know the type of activities in which children can integrate with others.

\section{Acknowledgements}

This research would not have been possible without the valuable collaboration of public and private institutions through their openness and collaboration, led to the design and dissemination of the software for SEN Children. The assiduous work of the professionals: Engineer Hugo Arias whose professional experience and visual impairment was a bulwark in the research process, and psychologists Ileana Altamirano and Pamela Espín, responsibles for conducting the psychological tests of the study group and Johann Jadán as technological support in videogames. Special acknowledgement to Carolina Jadán for allowing us to present her case as the core of this research program. This project has received support from of Universidad Tecnológica Indoamérica. We also acknowledge support from CITIC (Centro de Investigación en Tecnologías de la Información y la Comunicación) of Universidad de Costa Rica and CLEI Foundation let us to public this paper.

\section{References}

[1] CONADIS and INEC, " 2011 Census of Ecuador", Consejo Nacional de Discapacidades and Instituto Nacional de Estadística y Censos, 2011, http://www.conadis.gob.ec, http://www.ecuadorencifras.gob.ec.

[2] T. Hasselbring and C. Williams, "Use of Computer Technology to Help Students with Special Needs", The Future of Children, vol. 10, pp. 114, 2000.

[3] J. Jadán-Guerrero, "AINIDIU, CANDI, HELPMI: ICTs of a personal experience", Engineering Applications (WEA), 2012 Workshop on, pp. 1-7, 2012

[4] J. Jadán-Guerrero, " AINIDIU: An experience among university, organizations and government ", Computing Conference (CLEI), 2013 XXXIX Latin American , pp. 1-8, 2013

[5] PUCESA, "PUCE - Sede Ambato triunfó en concurso de robótica", Pontificia Universidad Católica del Ecuador Sede Ambato, November 2007, http://direccionestudiantes.blogspot.com/2007/11/estudiantes-deestela-y-de-teologa.html, http://direccionestudiantes.blogspot.com/2007/11/puce-sede-ambato-triunf-enconcurso-de.html.

[6] Cernuzzi Luca, Grau Ilse, Sánchez Jaime, "Aprendizaje de niños con discapacidad visual con agentes asistentes", Actas Contribuciones Tecnológicas para la discpacidad, I Jornadas CYTED sobre tecnologías de apoyo a la discpacidad, RIBERDISCAP, pp. 115-121, Paraguay, 2003.

[7] Borges, J.A. - DOSVOX - "Um novo horizonte para deficientes visuais" - Revista Técnica do Instituto Benjamin Constant - no. 3, Brazil, 1997

[8] Sánchez Jaime, Guerrero Luis, Sáenz Mauricio, Flores Héctor, "Modelo de desarrollo de aplicaciones móviles basadas en videojuegos para la navegación de personas ciegas", XIV TALLER INTERNACIONAL DE SOFTWARE EDUCATIVO, TISE'09, Santiago de Chile, 2009.

[9] Ferreyra, J. A., Méndez, A., \& Rodrigo, M. A. "El uso de las TIC en la Educación Especial : Descripción de un Sistema Informático para Niños Discapacitados Visuales en Etapa Preescolar”, Argentina, 2009

[10] FENCE, Federación Nacional de Ciegos del Ecuador, http://www.fenceec.org

[11] ONCE, Organización Nacional de Ciegos Españoles, http://www.once.es

[12] Doug Sapp, Yi Shang, " Intelligent Web Representatives", Dept. of Computer Engineering and Computer Science, University of Missouri-Columbia, 1999

[13] Indoamérica Virtual Magazine, "Lanzamiento de audiolibro 'El duendecillo de sombrero grande' ", http://utirevistavirtual.blogspot.com/2011/10/lanzamiento-de-audiolibro-el.html, 20/October/2011 
[14] FATLA, "Interview of winners of Audiobooks Contest held at Videoconference among Argentina, Venezuela, Ecuador and Costa Rica", Club de Reporteros 3D de la Fundación de Actualización de Tecnologías de Latianoamérica, 29/09/2013, http://www.youtube.com/watch?v=E3YRy6bgP6E

[15] Raisamo, R.; Hippula, A.; Patomaki, S.; Tuominen, E.; Pasto, V.; Hasu, M., "Testing usability of multimodal applications with visually impaired children," MultiMedia, IEEE, vol.13, no.3, pp.70,76, July-Sept. 2006

[16] Indoamérica Virtual Magazine, "La Universidad Indoamérica participa con proyectos de Investigación y gana en la UTCIENCIA 2012", Universidad Tecnológica Indoamérica, 23/January/2012, http://utirevistavirtual.blogspot.com/2012/01/la-universidad-indoamerica-participa.html,

[17] Diario El Comercio, "Feria UTCiencias 2012 - Universidad Técnica de Cotopaxi", Sección de Educación de Diario El Comercio, http://issuu.com/educaccion-impreso/docs/edu09052012/9, Universidad Tecnológica Indoamérica , 09/May/2012

[18] Indoamérica Virtual Magazine, "Investigador de la Universidad Indoamérica realiza presentación en la Conferencia Científica IEEE 2012 Workshop on Engineering Application", Universidad Tecnológica Indoamérica, $\quad \mathrm{http}$ ://uti-revistavirtual.blogspot.com/2012/05/universidad-indoamerica-representa-al.html, 10/May/2012

[19] Department of Education in the province The Napo, " Entrega de materiales tiflológicos", 09/February/2013, http://www.edunapo.gob.ec/index.php?option=com_content $\& v i e w=a r t i c l e \& i d=386$ :entrega-de-materialestiflologicos\&catid=40:relacionespublicas \&Itemid=3

[20] Espectador Azogues web site, "Noticias de la Provincia del Cañar: Estudiantes con discapacidad visual del $\begin{array}{llllll}\text { Azuay } & \text { C } & \text { Cañar } & \text { reciben }\end{array}$ http://espectadorazogues.blogspot.com/2013/03/estudiantes-con-discapacidad-visual-del.html

[21] Diario La Hora Manabí, "Entregarán importante donación'", 18/April/2013, ,http://www.lahora.com.ec/index.php/noticias/show/1101494253/1/Entregar\%C3\%A1n_importante_donaci\%C3\%B3n.html\#.UpUW18TuJhw

[22] Indoamérica Virtual Magazine, "Suscriben convenio marco de cooperación para fortalecer la inclusión de las personas con discapacidad en la educación.", Universidad Tecnológica Indoamérica, http://www.uti.edu.ec/index.php/convenios-institucionales/item/224-convenio-marco-uti-conadis, July 2013.

[23] UTI, "Virtual Learning Platform", Universidad http://www.indoamerica.us/campus/index.php/mnoticias/item/6-conadis

Tecnológica Indoamérica,

[24] Soundcloud website, "Audiobook: El Duendecito del sombrero grande", September 2013, https://soundcloud.com/user126357461/el-duendecito-del-sombrero

[25] Sampson, D.G.; Zervas, P.; Chloros, G., "ASK-LOM-AT 2.0: A Web-Based Tool for Educational Metadata Authoring of Open Educational Resources," Technology for Education (T4E), 2011 IEEE International Conference on , vol., no., pp.76,80, 14-16 July 2011

[26] Zervas, P.; Sampson, D.G., "Enhancing Educational Metadata with Mobile Assisted Language Learning Information," Advanced Learning Technologies (ICALT), 2010 IEEE 10th International Conference on , vol., no., pp.269,273, 5-7 July 2010

[27] Ahmed Seffah, Mohammad Donyaee, Rex B. Kline, Harkirat K. Padda, " Usability measurement and metrics: A consolidated model", Software Quality Journal N.14: 159-178, 2006

[28] Alec Webster, Joao Roe "Children with Visual Impairments: Social Interaction, Language and Learning.", Psychology Press, 1998 